Article

\title{
Fungi as Endophytes in Artemisia thuscula: Juxtaposed Elements of Diversity and Phylogeny
}

\author{
Andreea Cosoveanu * (D), Samuel Rodriguez Sabina and Raimundo Cabrera \\ Department Botanica, Ecologia \& Fisiologia Vegetal, Universidad de La Laguna, 38206 La Laguna, Tenerife, \\ Spain; samuelrguezsabina@gmail.com (S.R.S.); rcabrera@ull.edu.es (R.C.) \\ * Correspondence: andreeacosoveanu@gmail.com
}

Received: 25 October 2017; Accepted: 23 January 2018; Published: 27 January 2018

\begin{abstract}
Artemisia is a plant genus highly studied for its medicinal applications. The studies on the associated fungal endophytes are scarce. Ten plants specimens of Artemisia thuscula from Tenerife and La Palma were sampled to isolate the endophytic fungi. Identification of the endophytic fungi was based on morphology, Internal Transcribed Spacer (ITS) and Large Subunit (LSU) regions sequencing and indicates 37 fungal species affiliated to 25 fungal genera. Colonization rate varied among plants ( $\mathrm{CR}=25 \%$ to $92.11 \%$ ). The most dominant colonizers found were Alternaria alternata $(\mathrm{CF}=18.71 \%)$, Neofusicoccum sp. $(\mathrm{CF}=8.39 \%)$ and Preussia sp. $(\mathrm{CF}=3.23)$. Tendency for host specificity of most endophytic fungal species was observed. Sorensen-Dice index revealed that of 45 cases in the matrix, 27 of them were of zero similarity. Further, only one case was found to have 57\% similarity (TF2 and TF7) and one case with 50\% similarity (TF1 and TF4). The rest of the cases had values ranging between $11 \%$ and $40 \%$ similarity. Diversity indices like Brillouin, Margalef species richness, Simpson index of diversity and Fisher's alpha, revealed plants from La Palma with higher values than plants from Tenerife. Three nutrient media (i.e., potato dextrose agar-PDA, lignocellulose agar-LCA, and tomato juice agar-V8) were used in a case study and revealed no differences in terms of colonization rate when data was averaged. Colonization frequency showed several species with preference for nutrient medium $(63 \%$ of the species were isolated from only one nutrient medium). For the phylogenetic reconstruction using the Bayesian method, 54 endophytic fungal ITS sequences and associated GenBank sequences were analyzed. Ten orders (Diaporthales, Dothideales, Botryosphaeriales, Hypocreales, Trichosphaeriales, Amphisphaeriales, Xylariales, Capnodiales, Pleosporales and Eurotiales) were recognized. Several arrangements of genera draw the attention, like Aureobasidium (Dothideales) and Aplosporella (Botryosphaeriales) which are clustered with a recent ancestor $(B S=0.97)$.
\end{abstract}

Keywords: Artemisia; fungal endophytes; biodiversity; phylogeny

\section{Introduction}

Vascular plants species [1,2], aquatic plants and algae [3,4], mosses and ferns [5,6] examined to date are found to be hosts for endophytic bacteria and fungi [7]. Endophytic microorganisms have been isolated from different parts of plant-like scale primordia, meristem and resin ducts [8,9], leaf segments with midrib and roots, stem, bark, leaf blade, petiole [10], buds [11], and seeds [12]. Successful endophytic colonization is dependent on many factors including plant tissue type, plant genotype, the microbial taxon and strain type, and biotic and abiotic environmental conditions. Fungal endophytes aid plants to withstand and tolerate unfavorable environmental conditions $[13,14]$ and also promote plant growth $[15,16]$. These inhabitants can produce the same or similar secondary metabolites [17-20] as their host and play vital roles in vivo such as signaling, defense, and regulation of the symbiosis [21]. Mainly investigations are based on their use as biochemical tools and the end products are to be used in pharmaceutics, industry, and agriculture. 
Artemisia is a plant highly evaluated for medicinal and biopesticide traits. A survey of the literature shows this plant genus to be in the hot spot among researchers with over 11,200 publications in Scopus library. Even though Artemisia is a large plant genus with species producing a variety of interesting and active compounds, its endophytic communities are under investigated. The identification of the fungal endophytes in Artemisia spp. is made mainly based on morphological characterization and molecular analysis using nuclear ribosomal DNA sequences, including both the internal transcribed spacers and the $5.8 \mathrm{~S}$ gene region. To the best of our knowledge, there have been only four studies which investigate the phylogenetic analysis of the Artemisia spp. fungal endophytes [22-25]. In terms of diversity, the studies are also scarce but interesting facts are brought to light in terms of diversity and plant colonization. For instance, Yuan et al., 2011 [26] performed a comparative study related to infection frequency between cultivated plants and wild plants of Artemisia annua. The results revealed slightly higher infection frequency of the endophytic fungi in cultivated roots $(20.9 \%)$ than in native roots $(16.7 \%)$. Further, authors described that the naturally regenerated roots harbored richer fungal genotypes, which supports the hypothesis that wild plant species are predisposed to host rich and novel mycoflora [27]. It is worth mentioning that Qian et al., 2014 [27] reported the presence of Rhodotorula sp. and Fusarium sp. in Artemisia argyi for the first time. The endophytic fungi associated with Artemisia nilagirica were investigated and one strain of Pythium intermedium (Oomycota) and one strain of Rhizopus oryzae (Mucoromycota) were isolated among the majority clade of Ascomycota [28]. Huang et al., 2009 [24] classified 108 fungal isolates obtained from three medicinal plant species Artemisia capillaris, Artemisia indica and Artemisia lactiflora using morphological identification and among the three plant hosts, the highest endophytic colonization rate occurred in Artemisia capillaris, which exhibited highest fungal diversity. Five fungal isolates belonging to Aureobasidium pullulans, Ephelis, Pestalotiopsis, and Pleosporaceae, were only recovered from Artemisia capillaris. Xylaria species was reported to be dominant endophytic fungi in Artemisia indica. Seven Artemisia species were sampled in two locations (Qichun and Wuhan in China) and 21 fungal endophytic species belonging to: Diaporthe, Colletotrichum, Nigrospora, Botryosphaeria, Aspergillus, Penicillium, Neofusicoccum, Cercospora, Rhizoctonia, Alternaria, and Curvularia were found [23]. The highest incidences of colonization frequency per plant host revealed Nigrospora sphaerica in Artemisia sp., Nigrospora oryzae in Artemisia argyi, Alternaria alternata in Artemisia subulata and Artemisia tangutica and Botryosphaeria dothidea in Artemisia lavandulifolia. The authors report for the first time Nigrospora, Neofusicoccum and Curvularia species in Artemisia spp.

Artemisia thuscula is an endemic plant of Canary Islands and community of endophytes housed inside its plant tissues remains unexplored. With the idea of exploring endemic medicinal plants for useful and underexplored fungal endophytes, we strategically pinned down to Artemisia thuscula that has been harboring in western areas of islands i.e., Tenerife and La Palma, for ages. Elements of phylogeny and diversity were framed for the strains obtained from both islands with a case study of Tenerife where diversity was intended to be enhanced by using different nutrient media and stem ages. Questions on host specificity were explored, having one plant species and various collection locations.

\section{Materials and Methods}

\subsection{Plants Sampling}

Plants of Artemisia thuscula species were collected from Canary Islands (La Palma and Tenerife). 10 plants specimens were sampled in total. Three plants were sampled from La Palma and seven plants were sampled from Tenerife; GPS coordinates are mentioned in Table 1. In situ, plants were observed for their healthy appearance prior to the sampling, only those individuals that did not show symptoms of attack by pest or disease were selected. From each plant only stems segments were cut, labeled and kept in paper bags inside zip-locked bags at $\mathrm{T}=4-5^{\circ} \mathrm{C}$ until transported to the laboratory and then processed within $24 \mathrm{~h}$. Identification of the plant species was performed using classical morphological examination. The plants were deposited at the University of La Laguna (ULL) herbarium (TFC). 
Table 1. Details of collected Artemisia species plants.

\begin{tabular}{|c|c|c|c|c|c|c|}
\hline $\begin{array}{c}\text { Plant } \\
\text { Species }\end{array}$ & Plant Code & $\begin{array}{l}\text { Collection } \\
\text { Place }\end{array}$ & Country/Island & $\begin{array}{c}\text { Herbarium Type } \\
\text { Details }\end{array}$ & $\begin{array}{l}\text { GPS UTM } \\
\text { Latitude }\end{array}$ & $\begin{array}{l}\text { GPS UTM } \\
\text { Longitude }\end{array}$ \\
\hline A. thuscula & LP1 & El Granel & La Palma & TFC. No. 52658 & $28^{\circ} 45^{\prime} 47.43^{\prime \prime} \mathrm{N}$ & $17^{\circ} 45^{\prime} 7.47^{\prime \prime} \mathrm{W}$ \\
\hline A. thuscula & LP2 & San Bartolo & La Palma & TFC. No. 52659 & $28^{\circ} 46^{\prime} 1.08^{\prime \prime} \mathrm{N}$ & $17^{\circ} 45^{\prime} 26.07^{\prime \prime} \mathrm{W}$ \\
\hline A. thuscula & LP4 & Tigalate & La Palma & TFC. No. 52661 & $28^{\circ} 32^{\prime} 35.45^{\prime \prime} \mathrm{N}$ & $17^{\circ} 48^{\prime} 41.29^{\prime \prime} \mathrm{W}$ \\
\hline A. thuscula & TF8 & El Palmar & Tenerife & TFC. No. 52669 & $28^{\circ} 20^{\prime} 35.18^{\prime \prime} \mathrm{N}$ & $16^{\circ} 51^{\prime} 26.57^{\prime \prime} \mathrm{W}$ \\
\hline A. thuscula & TF7 & Granadilla & Tenerife & TFC. No. 52668 & $28^{\circ} 06^{\prime} 54.19^{\prime \prime} \mathrm{N}$ & $16^{\circ} 34^{\prime} 51.14^{\prime \prime} \mathrm{W}$ \\
\hline A. thuscula & TF4 & Caletillas & Tenerife & TFC. No. 52665 & $28^{\circ} 23^{\prime} 2.03^{\prime \prime} \mathrm{N}$ & $16^{\circ} 21^{\prime} 54.71^{\prime \prime} \mathrm{W}$ \\
\hline A. thuscula & TF1 & Mesa Mota & Tenerife & TFC. No. 52662 & $28^{\circ} 30^{\prime} 38.75^{\prime \prime} \mathrm{N}$ & $16^{\circ} 19^{\prime} 20.55^{\prime \prime} \mathrm{W}$ \\
\hline A. thuscula & TF2 & Mesa Mota & Tenerife & TFC. No. 52663 & $28^{\circ} 30^{\prime} 38.75^{\prime \prime} \mathrm{N}$ & $16^{\circ} 19^{\prime} 20.55^{\prime \prime} \mathrm{W}$ \\
\hline A. thuscula & TF5 & San Andres & Tenerife & TFC. No. 52666 & $28^{\circ} 30^{\prime} 51.01^{\prime \prime} \mathrm{N}$ & $16^{\circ} 11^{\prime} 41.94^{\prime \prime} \mathrm{W}$ \\
\hline A. thuscula & TF3 & Taborno & Tenerife & TFC. No. 52664 & $28^{\circ} 33^{\prime} 18.36^{\prime \prime} \mathrm{N}$ & $16^{\circ} 15^{\prime} 53.10^{\prime \prime} \mathrm{W}$ \\
\hline
\end{tabular}

\subsection{Fungal Endophyte Isolation}

Surface sterilization method was used to suppress epiphytic microorganisms from the plant [23]. Thus, stem fragments were first washed with sterile water, then immersed in $70 \%$ ethanol for $1 \mathrm{~min}$, followed by an immersion in 15\% sodium hypochlorite for $1 \mathrm{~min}$, again in $70 \%$ ethanol for $1 \mathrm{~min}$ and lastly were washed with sterile distilled water. To assure a successful sterilization, fragments were rolled on potato dextrose agar (PDA) medium and drops of last step sterilization water were poured on medium, as a control check for complete sterilization. After this process, plant material was dried on sterile blotting sheet, excised in pieces of $2 \mathrm{~cm}$ and cut longitudinally with a sterile scalpel. Segments were placed in PDA (Sigma-Aldrich, St. Louis, MI, USA) Petri plates amended with tetracycline $\left(10 \mathrm{mg} \mathrm{L}^{-1}\right)$. Plates incubated with the plant segments were incubated at $25^{\circ} \mathrm{C}$ in the dark for two weeks and observed daily for fungal growth. When fungal outgrowth from the plant tissues occurred observations on emerged fungi were made. Only the fungi with different morphological characteristics were subcultured. Eventually, when an endophyte was acquired in pure culture it was preserved in Czapek medium (Fluka Analytical, Sigma-Aldrich), $\mathrm{T}=5{ }^{\circ} \mathrm{C}$ and in glycerol ( $\geq 99.5$, Sigma-Aldrich) $20 \%$ in deionized $\mathrm{H}_{2} \mathrm{O}, \mathrm{T}=-32{ }^{\circ} \mathrm{C}$ and identified. To analyze the fungal diversity, each replicate of the distinct stem fragments was noted. To enhance bioprospection and diversity, variable nutritive media were utilized to incubate stem fragments (with ages less than one year and more than one year) of eight plants from Tenerife. Therefore, V8 tomato juice agar and lignocellulose agar (LCA) [29] media were additionally used. All the reagents were purchased from Sigma-Aldrich, except Agar Agar-GUINAMA (Valencia, Spain) and Potassium chloride-PanReac AppliChem (Barcelona, Spain).

\subsection{Fungal Endophyte Collection and Maintenance}

Every isolate and its plant origin were dully recorded for calculation of colonization rate from host, counting the same isolate identification only once if it emerges from the same plant segment. After purification of each isolate, it was subjected to microscopical observations followed by molecular analysis to identify at genus and/or species level. Isolates are presently maintained in three types of media: Czapek, $\mathrm{T}=5{ }^{\circ} \mathrm{C}$; mineral oil (Sigma-Aldrich), $\mathrm{T}=5{ }^{\circ} \mathrm{C}$ and glycerol (Sigma-Aldrich) $20 \%$ $\mathrm{diH}_{2} \mathrm{O}, \mathrm{T}=-80^{\circ} \mathrm{C}$. For short term use, fungal isolates were maintained on PDA, $25^{\circ} \mathrm{C}$.

\subsection{Morphological Identification}

Prior to taxonomic identification, a preliminary classification was made to avoid the selection of identical strains arising from the same plant individual, separating isolates into morphotypes. Observations targeted characteristics related to the colony and medium as: colony shape, texture and colour; exudates, medium colour and growth rate. For the microscopic observations, a strain was inoculated onto a PDA Petri plate and a sterile cover slide was attached at two centimeters. Once the growth of the fungus partially covered the cover slide, the slide was removed, inverted on a slide with cotton blue (for the slightly coloured colonies) and observed under microscope. 


\subsection{Molecular Identification}

Out of several procedures for genomic DNA extraction, the most efficient protocol, although time consuming, was the one described by Shu et al., 2014 [20] to which the following modifications were made. Samples were centrifuged for $15 \mathrm{~min}$ at $12,000 \mathrm{rpm}$; after the chloroform $(\geq 99.5$, Sigma-Aldrich) procedure the upper phase was mixed with $10 \%$ Sodium acetate (ReagentPlus ${ }^{\circledR}$, $\geq 99.0 \%$, Sigma-Aldrich) and 60\% Isopropyl alcohol (Aldrich $\geq 97.0 \%$, Sigma-Aldrich), incubated for $10 \mathrm{~min}$ at $-30^{\circ} \mathrm{C}$ and centrifuged (10 min, 12,000 rpm). Finally, the pellet was washed twice with $75 \%$ ethanol (before maintained at $-20^{\circ} \mathrm{C}$ ) and centrifuged (10 min, 12,000 rpm). The solvent was removed by evaporation, keeping the sample in the laminar flow cabinet. The purified DNA was suspended in $20 \mu \mathrm{L}$ TE buffer (10 mM Tris- $\mathrm{HCl}$, pH 8.0, 1 mM EDTA); all reagents were purchased from Sigma-Aldrich. RNase A was added, and the sample was incubated for 1 hour at room temperature (long-term storage at $-32{ }^{\circ} \mathrm{C}$ ).

The second protocol for DNA extraction involves no purification of DNA but acceptable results were garnered (around 50\% samples succeeded). $20 \mu \mathrm{L}$ of TE buffer was pipetted into a microtube and glass beads (diameter $=0.4-0.6 \mathrm{~mm}$ ) were added to make up $3 / 4$ of the reagent's volume. A small quantity of fungal mycelium was added $(2-5 \mathrm{~mm} / 2-3 \mathrm{mg})$ with a needle. Samples were homogenized using FastPrep $24^{\mathrm{TM}} 5 \mathrm{G}$ (MP Bio, Santa Ana, California, USA) at $4 \mathrm{~m} / \mathrm{s}, 20 \mathrm{~s}$. Subsequently samples were centrifuged at 13,000 rpm for $1 \mathrm{~min}$ and maintained on ice. One $\mu \mathrm{L}$ of the supernatant was used for the PCRs.

The third and fourth protocol involved two genomic DNA extraction kits. First one used was E.Z.N.A. Fungal DNA Kit according to the manufacturer indications (OMEGA bio-tek, Norcross, Georgia, USA) with overall good results (around $80 \%$ of the samples succeeded). The second one tested was Fungi/Yeast Genomic DNA Isolation Kit, according to the manufacturer indications (NORGEN Biotek, Thorold, ON, Canada) with overall good results also (approximately $70 \%$ of the samples succeeded).

The fourth protocol approaches nucleic acid extraction by application of silica coupled to magnetic particles, which is efficient and automated. Genomic fungal DNA was extracted using Maxwell 16 Mouse Tail DNA purification kit. The Promega kit is designed for automated DNA extraction from tissue samples using the Maxwell ${ }^{\mathrm{TM}} 16$ platform (Promega BioSciences, San Luis Obispo, CA, USA). This protocol was performed at the University Institute of Tropical Diseases and Public Health of the Canary Islands, University of La Laguna.

Molecular identification of the fungal Dicarya strains was performed using ITS1 (5'-TCCGTAGGTGAACCTGCGG-3') and ITS4 (5'-TCCTCCGCTTATTGATATGC- $\left.3^{\prime}\right)$ primer pair to amplify the 5.8S rDNA and the two internal transcribed spacers ITS1 and ITS2 [30] for the majority of the samples and NL-1 (5'-GCA TAT CAA TAA GCG GAG GAA AAG-3') and NL-4 (5'-GGT CCG TGT TTC AAG ACG G-3 $3^{\prime}$ ) primer pair to amplify the $5^{\prime}$ end of $28 \mathrm{~S}$ rDNA spanning domains D1 and D2) [31]. PCRs were performed in a total volume of $25 \mu \mathrm{L}$ containing $10 \mathrm{ng}$ genomic DNA, $0.5 \mu \mathrm{M}$ primer, $200 \mu \mathrm{M}$ dNTPs, 1X Buffer Taq, 0.0125U of Taq DNA Polymerase. For ITS sequences, PCR cycling parameters were carried out according to Shu et al. 2014 [20] with slight modifications: $94{ }^{\circ} \mathrm{C}$ for $2.5 \mathrm{~min} ; 40$ cycles of $94{ }^{\circ} \mathrm{C}$ for $30 \mathrm{~s}, 58^{\circ} \mathrm{C}$ for $30 \mathrm{~s}$, and $72{ }^{\circ} \mathrm{C}$ for $1 \mathrm{~min}$; and a final extension at $72{ }^{\circ} \mathrm{C}$ for $10 \mathrm{~min}$. For $28 \mathrm{~S}$ rDNA domain, the PCR conditions were denaturation for 4 min at $95{ }^{\circ} \mathrm{C}$ followed by $45 \mathrm{~s}$ at $95^{\circ} \mathrm{C}$ and then annealing for $45 \mathrm{~s}$ at $58{ }^{\circ} \mathrm{C}, 1 \mathrm{~min}$ at $72{ }^{\circ} \mathrm{C}$, followed by an extension at $72{ }^{\circ} \mathrm{C}$ for $5 \mathrm{~min}$. The final step was at $16^{\circ} \mathrm{C}$ for $5 \mathrm{~min}$. A total of 40 cycles were performed. All PCR products were detected by agarose gel electrophoresis (110V, $35 \mathrm{~min}$, on $2 \%$ agarose gels, 1X TAE Buffer) loading $5 \mu \mathrm{L}$ PCR product, $1 \mu \mathrm{L}$ Loading Buffer (6X) and $2 \mu \mathrm{L}$ SYBR Green I (Sigma-Aldrich; dilution 1:10,000). PCR and electrophoresis reagents were purchased from Sigma-Aldrich. PCR products were purified using GenElute ${ }^{\mathrm{TM}}$ PCR Clean-Up Kit (Sigma-Aldrich) and sequenced by Sequencing Services SEGAI (La Laguna, Spain). The sequences were run through the BLASTN search page using Megablast program (National Center for Biotechnology Information; Bethesda MD, USA) where the 
most identical hits and their accession numbers were obtained. Further, only ITS sequences were used for the phylogenetic analysis, therefore details on $28 \mathrm{~S}$ sequenced strains are listed in Table 2.

Table 2. Artemisia fungal endophytic strains: codes, identities as per morphology, $28 \mathrm{~S}$ rDNA LSU sequences and their most similar hits from Genbank with accession numbers and values.

\begin{tabular}{|c|c|c|c|c|c|c|c|}
\hline EF Code & $\begin{array}{c}\text { Assigned } \\
\text { Species/Species } \\
\text { Complex }\end{array}$ & $\begin{array}{c}\text { GenBank } \\
\text { Identified Seq. }\end{array}$ & Max Score & $\begin{array}{l}\text { Total } \\
\text { Score }\end{array}$ & E Value & $\begin{array}{c}\text { Max } \\
\text { Identity } \\
(\%) \\
\end{array}$ & $\begin{array}{c}\text { Accession } \\
\text { No. } \\
\end{array}$ \\
\hline HLP1 & A. alternata & A. alternata & 1107 & 1107 & 0 & 99 & KX609781.1 \\
\hline HLP31 & Fungus sp. 1 & $\begin{array}{l}\text { Uncultured fungus } \\
\text { clone }\end{array}$ & 135 & 724 & $2.00 \times 10^{-27}$ & 100 & KP843503.1 \\
\hline HLP5 & A. alternata & A. alternata & 1052 & 1052 & 0 & 99 & KF751621.1 \\
\hline HLP9 & Preussia sp. 1 & P. mimoides & 1000 & 1000 & 0 & 97 & KF557659.1 \\
\hline HTF25 & Alternaria sp. 6 & A. brassicicola & 289 & 289 & $5.00 \times 10^{-74}$ & 77 & AF397222.1 \\
\hline HTF37 & A. alternata & A. alternata & 982 & 982 & 0 & 96 & KX609781.1 \\
\hline HTF42 & Neofusicoccum australe & N. australe & 1036 & 1036 & 0 & 97 & KF766367.1 \\
\hline HTF49 & Neofusicoccum australe & N. australe & 1058 & 1058 & 0 & 98 & HM176550.1 \\
\hline HTF50 & A. alternata & A. alternata & 971 & 971 & 0 & 98 & KF543048.1 \\
\hline
\end{tabular}

\subsection{Phylogenetic Analysis}

ITS sequences [i.e., endophytic fungi-Table 3, their most similar hits from GenBank (NCBI, Bethesda MD, USA) and type sequences of the selected taxa] were aligned with the multiple alignment program ClustalW [32] as implemented in Mega 6.0 (Molecular Evolutionary Genetics Analysis) [33] and indels corrected manually to minimize alignment gaps [34]. Designated outgroup was Caloscypha fulgens (GenBank Accession No. DQ491483). After the exclusion of non-overlapping leading/trailing gaps the length of the alignment was $603 \mathrm{bps}$. Because of the high number of indels, these were recoded as a binary matrix by means of the simple indel coding algorithm [35], appending the fragments to the nucleotide data as additional characters, as implemented in FastGap 1.21 (Department of Biosciences, Aarhus University, Denmark) [36]. This "indel matrix" was used in all Bayesian and maximum likelihood analyses. Formerly, Gblocks program (hosted at www.phylogeny.fr) was used to eliminate poorly aligned positions and divergent regions [37]. Best-fit models were compared in jModelTest 2 according to Bayesian Information Criterion (BIC) [38]. Best fit according to the BIC criterion model $(\mathrm{K} 80+\mathrm{G})$ was selected to reconstruct the Bayesian tree. Bayesian Inference analysis was conducted with MrBayes 3.2.3 (hosted by Mobyle SNAP Workbench, North Carolina State University) [39] and run for $1 \times 10^{7}$ generations with a sampling frequency of 100 generations. Of the resulting trees, the first 25,000 trees were discarded as burn-in and the following 75,001 were used to estimate topology and tree parameters. The percentage number of times a node occurred within these 75,001 was interpreted as the posterior probability of the node [40]. Convergence of the runs was indicated by an average standard deviation of split frequencies between duplicate runs of less than 0.01 . The consensus trees were drawn using Treegraph 2 software (Institute for Evolution and Biodiversity, University of Munster, Germany) [41] and edited with Adobe Illustrator CS3 (Adobe Systems Incorporated, San Jose, CA, USA). 
Table 3. Endophytic fungi isolated from A. thuscula and used for the phylogenetic analysis: codes, identity and accession numbers of the ITS sequences.

\begin{tabular}{|c|c|c|}
\hline Strain Code & Identity & Accession No. \\
\hline HLP12 & Phoma sp. & MG025848 \\
\hline HLP14 & Preussia sp. & MG025849 \\
\hline HLP15 & Diaporthe phaseolorum & MG025850 \\
\hline HLP19 & Alternaria alternata & MG025851 \\
\hline HLP23 & Diaporthe novem & MG025852 \\
\hline HLP24 & Nigrospora oryzae & MG025853 \\
\hline HLP25 & Camarosporium brabeji & MG025854 \\
\hline HLP27 & Coniothyrium sp. & MG025855 \\
\hline HLP3 & Aspergillus flavus & MG025856 \\
\hline HLP32 & Alternaria alternata & MG025857 \\
\hline HLP37 & Diaporthe sp. & MG025858 \\
\hline HLP40 & Alternaria alternata & MG025859 \\
\hline HLP43 & Tremateia sp. & MG025860 \\
\hline HLP44 & Neoplatysporoides aloicola & MG025861 \\
\hline HLP45 & Neofusicoccum parvum & MG025862 \\
\hline HLP46 & Neofusicoccum parvum & MG025863 \\
\hline HLP7 & Paraphoma chrysanthemicola & MG025864 \\
\hline HTF23 & Nectria mauritiicola & MG025865 \\
\hline HTF26 & Stachybotrys longispora & MG025866 \\
\hline HTF27 & Stemphylium solani & MG025867 \\
\hline HTF30 & Aplosporella prunicola & MG025868 \\
\hline HTF31 & Stemphylium solani & MG025869 \\
\hline HTF40 & Biscogniauxia mediterranea & MG025870 \\
\hline HTF41 & Alternaria alternata & MG025871 \\
\hline HTF44 & Alternaria alternata & MG025872 \\
\hline HTF46 & Alternaria alternata & MG025873 \\
\hline HTF48 & Phoma sp. & MG025874 \\
\hline HTF52 & Alternaria alternata & MG025875 \\
\hline HTF53 & Alternaria alternata & MG025876 \\
\hline HTF62 & Neofusicoccum paroum & MG025877 \\
\hline HTF64 & Pestalotiopsis sp. & MG025878 \\
\hline HTF66 & Aureobasidium pullulans & MG025879 \\
\hline HTF68 & Stemphylium solani & MG025880 \\
\hline HTF70 & Cladosporium sp. & MG025881 \\
\hline HTF74 & Preussia australis & MG025882 \\
\hline HTF76 & Alternaria alternata & MG025883 \\
\hline HTF79 & Phoma sp. & MG025884 \\
\hline HTF81 & Preussia sp. & MG025885 \\
\hline HTF82 & Biscogniauxia mediterranea & MG025886 \\
\hline HTF83 & Stemphylium solani & MG025887 \\
\hline HTF84 & Preussia sp. & MG025888 \\
\hline HTF85 & Preussia sp. & MG025889 \\
\hline
\end{tabular}

\subsection{Diversity Analysis}

The colonization rate $(\mathrm{CR} \%)$ was calculated as the total number of stem fragments in a sample (plant/nutritive medium) yielding at least one isolate divided by the total number of stem fragments in that sample. Colonization frequency ( $\mathrm{CF} \%$ ) was calculated as the total number of fragments in a sample (plant/location) colonized by a species divided by the total number of fragments plated. For the diversity of endophytic fungi, the Margalef index, Brillouin index, Fisher's alpha index and Simpson's dominance index were used. Margalef index [42] measures species richness while Brillouin index combines richness and evenness. The Margalef index was calculated using formula $d=(S-1) / \ln N$, where $S$ is the number of species and $N$ is the number of individuals in the sample. The Brillouin index $[43,44]$ was calculated using formula: $\mathrm{HB}=\left(\ln N !-S \ln n_{i} !\right) / N$, where $N$ is the total number 
of individuals, $S$ is the number of taxa and $n_{i}$ is the number of individuals belonging to $i$ species. Fisher's logarithmic series model [45] is a species-abundant model and describes the relationship between the number of species and the number of individuals of those species. It was calculated using formula $S=a \times \ln (1+n / a)$, where $S$ is number of taxa, $n$ is the number of individuals and a is the Fisher's alpha. The dominance of Simpson [46] was calculated according to the formula $D=1-\sum\left[n_{i\left(n_{i}-1\right)} / N(N-1)\right]$, where $n_{i}$ is the number of individuals belonging to $i$ species and $N$ is the total number of individuals. The Sorensen-Dice coefficient of similarity $[47,48]$ which expresses the beta diversity was employed to compare the similarity of endophytic fungi communities regarding species composition between two host plants, nutrient media and stem ages. The Sorensen-Dice coefficient is calculated with the formula $\mathrm{QS}=2 C /(A+B)$ where $A$ and $B$ are the species numbers in samples $A$ and $B$, respectively, and $C$ is the number of species shared by the two samples. The Sorensen-Dice coefficient weighs more the joint occurrences than the mismatches and is expressed with values between 0 (no similarity) and 1 (absolute similarity). This index was used to assess host preference and spatial heterogeneity by describing the similarity of endophytic communities within ten host plants at distinct sampling sites. Nevertheless, as the coefficient analyses the presence/absence data, no judgments on abundance or rare taxa can be pursued. A binary matrix was produced and used to calculate the similarity matrix and to plot a dendrogram based on an unweighted paired group method of arithmetic average (UPGMA) cluster analysis. For the diversity indices, PAST software version 3.15 (copyright Hammer \& Harper, Natural History Museum, University of Oslo, Norway) was used.

\section{Results and Discussion}

\subsection{Fungal Endophytic Diversity in Artemisia Species}

\subsubsection{Colonization Rate and Colonization Frequency of Endophytic Fungi in Artemisia thuscula}

In this study, the employed analyses indicate that 37 fungal species and 25 fungal genera were isolated from 10 plants of Artemisia thuscula. Colonization rate (further CR) shows how much a plant can be colonized within predetermined conditions. It is valuable information as different plants showed distinct values of this index; therefore, low values could express plants poor in endophytic fungi culturable in the given conditions.

To calculate the colonization frequency (CF) of fungal endophytes in Artemisia species plants, we have considered same fungal endophytic species isolated from two or more plant fragments as being a distinct isolate belonging to the same species. Therefore, if the same species was isolated twice from the same plant fragment, it was considered only one time. This issue is to be expected at isolation moment, when no precise differentiation between the isolates can be defined, and only once purified and further analyzed then only the strain received a final identification. The CF\% gives a hint over the distribution and abundance of a certain fungal species in a sample (i.e., plant/location/region). To know the "area" of the distribution and abundance of a certain endophytic fungal species, we have analyzed the data per plant individual or plant location, plant species, and plant region. Regions were grouped here as: La Palma Island and Tenerife Island. This way we can have an overview on where certain fungal species are more abundant or rare, as well as if there is a relation between their distribution and plant-specific parameters.

In Artemisia thuscula, only one plant out of 10 had a colonization rate value over 90\% (LP2). The lowest values $(\mathrm{CR} \%=25)$ were recorded for three plants (TF8, TF7 and TF3). Interestingly, as per variable geographical location there is a considerable variation between La Palma Island and Tenerife Island, with the former having the most colonized plant individuals (Table 4). 
Table 4. Colonization rate (CR) of fungal endophytes in Artemisia thuscula collected in Canary Islands.

\begin{tabular}{ccccc}
\hline Collection Place & Region & Plant Number & Locality Code & CR\% \\
\hline El Granel & La Palma & ${ }^{*}$ LP1 & EG & 48.28 \\
El Palmar-Teno & Tenerife & $* *$ TF8 & EP & 25.00 \\
Granadilla & Tenerife & TF7 & GR & 25.00 \\
Igueste Caletillas & Tenerife & TF4 & IC & 50.00 \\
Mesa Mota & Tenerife & TF1 & MM & 62.50 \\
Mesa Mota & Tenerife & TF2 & MM & 62.50 \\
San Andrés & Tenerife & TF5 & SA & 62.50 \\
San Bartolo & La Palma & LP2 & SB & 92.11 \\
Taborno & Tenerife & TF3 & TA & 25.00 \\
Tigalate & La Palma & LP4 & & 55.00 \\
AVG & & & & 50.78 \\
SD & & & & 16.13 \\
\hline
\end{tabular}

${ }^{*} \mathrm{LP}=\mathrm{La}$ Palma; ${ }^{* *} \mathrm{TF}=$ Tenerife; $\mathrm{AVG}=$ average; $\mathrm{SD}=$ standard deviation.

Artemisia thuscula cannot escape of the "omnipresence" of Alternaria alternata, this species was isolated from eight plants but with relevant differences in the frequency, $\mathrm{CF} \%=15-50 \%$. A notable presence is remarked here, Neofusicoccum australe, isolated from three plants at relatively high values $(\mathrm{CF} \%=25)$ when considering that the maximum value is 50. Moreover, the Neofusicoccum genus, consisting here of three species was isolated from eight plants, one of which revealed a CF\% of 34.21. Interestingly, around 70\% of the fungal species in Artemisia thuscula were isolated from only one plant each (Table 5). This suggests a host specificity which was also exhibited by the low and moderate values of Sorensen-Dice coefficient when the similarity of the endophytic assemblages was analyzed (see further Diversity indices for endophytic fungi in Artemisia thuscula).

Table 5. Colonization frequency on potato dextrose agar (PDA) medium of fungal endophytic species in Artemisia thuscula plants.

\begin{tabular}{|c|c|c|c|c|c|c|c|}
\hline $\begin{array}{l}\text { Plant } \\
\text { Code }\end{array}$ & $\begin{array}{l}\text { Locality } \\
\text { Code }\end{array}$ & EF Species & $\mathrm{CF} \%$ & $\begin{array}{l}\text { Plant } \\
\text { Code }\end{array}$ & $\begin{array}{l}\text { Locality } \\
\text { Code }\end{array}$ & EF Species & $\mathrm{CF} \%$ \\
\hline LP1 & EG & Alternaria alternata & 24.14 & LP2 & SB & Preussia sp. 3 & 2.63 \\
\hline LP1 & EG & Alternaria sp. 5 & 13.79 & LP2 & SB & Tremateia sp. 1 & 2.63 \\
\hline LP1 & EG & Aspergillus flavus & 6.90 & LP4 & TIG & Curvularia lunata & 5.00 \\
\hline LP1 & EG & Diaporthe novem & 3.45 & LP4 & TIG & Neofusicoccum sp. 1 & 5.00 \\
\hline LP1 & EG & Fungus sp. 1 & 3.45 & LP4 & TIG & $\begin{array}{l}\text { Paraphoma cf. } \\
\text { chrysantemicola }\end{array}$ & 5.00 \\
\hline LP1 & EG & Nigrospora oryzae & 3.45 & TF1 & MM & Alternaria alternata & 25.00 \\
\hline LP1 & EG & Penicillium viridicatum & 3.45 & TF1 & MM & Thielavia sp. 1 & 8.33 \\
\hline LP1 & EG & Phoma sp. 3 & 3.45 & TF2 & MM & Alternaria alternata & 50.00 \\
\hline LP1 & EG & Pleosporales sp. 2 & 6.90 & TF2 & MM & $\begin{array}{l}\text { Biscogniauxia } \\
\text { mediterrranea }\end{array}$ & 12.50 \\
\hline LP1 & EG & Preussia sp. 3 & 3.45 & TF2 & MM & Neofusicoccum australe & 12.50 \\
\hline LP2 & SB & Diaporthe phaseolorum & 7.89 & TF5 & SA & Alternaria alternata & 12.50 \\
\hline LP2 & SB & Diaporthe sp. 1 & 5.26 & TF5 & SA & Alternaria sp. 6 & 12.50 \\
\hline LP2 & SB & Dothideomycetes sp. 1 & 2.63 & TF5 & SA & Macrophomina phaseolina & 25.00 \\
\hline LP2 & SB & Fungus sp. 1 & 2.63 & TF5 & SA & Stachybotrys longispora & 12.50 \\
\hline LP2 & SB & Neofusicoccum parvum & 13.16 & TF7 & GR & Alternaria alternata & 25.00 \\
\hline LP2 & SB & Neofusicoccum sp. 3 & 34.21 & TF7 & GR & Neofusicoccum australe & 25.00 \\
\hline LP2 & SB & Neoplatysporoides aloicola & 5.26 & TF7 & GR & Stemphylium solani & 25.00 \\
\hline LP2 & SB & Nigrospora sp. 2 & 2.63 & TF8 & EP & Camarosporium sp. 1 & 12.50 \\
\hline LP2 & SB & Pleosporales sp. 3 & 2.63 & TF8 & $\mathrm{EP}$ & Phoma sp. 1 & 12.50 \\
\hline
\end{tabular}

EG = El Granel; SB = San Bartolo; TIG = Tigalate; MM = Mesa Mota; TA = Taborno; IC = Igueste Caletillas; SA = San Andres; GR = Granadilla; EP = El Palmar. 
34 endophytic fungal species were isolated from Artemisia thuscula (Table 6) and their frequency varied within a low range with two exceptions: Alternaria alternata $(\mathrm{CF} \%=18.71)$ and Neofusicoccum $\mathrm{sp}$. $3(\mathrm{CF} \%=8.39)$.

Table 6. Colonization frequency of fungal endophytic species in Artemisia thuscula (overall $\mathrm{CF} \% /$ plant species).

\begin{tabular}{cccc}
\hline EF Species & CF\% & EF Species & CF\% \\
\hline Alternaria alternata & 18.71 & Neofusicoccum parvum & 3.87 \\
Alternaria sp. 5 & 3.23 & Neofusicoccum sp. 1 & 0.65 \\
Alternaria sp. 6 & 0.65 & Neofusicoccum sp. 3 & 8.39 \\
Aspergillus flavus & 1.94 & Neoplatysporoides aloicola & 1.29 \\
Aureobasidium pullulans & 0.65 & Nigrospora oryzae & 0.65 \\
Biscogniauxia & 0.65 & Nigrospora sp. 2 & 0.65 \\
mediterrranea & & Paraphoma & 0.65 \\
Camarosporium bradgi & 0.65 & chrysantemicola & 0.65 \\
Camarosporium sp. 1 & 0.65 & Penicillium viridicatum & 1.29 \\
Coniothyrium sp. 1 & 0.65 & Phoma sp. 1 & 0.65 \\
Curvularia lunata & 0.65 & Phoma sp. 3 & 1.29 \\
Diaporthe novem & 0.65 & Pleosporales sp. 2 & 0.65 \\
Diaporthe phaseolorum & 1.94 & Pleosporales sp. 3 & 3.23 \\
Diaporthe sp. 1 & 1.29 & Preussia sp. 1 & 1.29 \\
Dothideomycetes sp. 1 & 0.65 & Preussia sp. 3 & 0.65 \\
Fungus sp. 1 & 1.29 & Stachybotrys longispora & 0.65 \\
Macrophomina phaseolina & 1.29 & Stemphylium solani & 1.94 \\
Neofusicoccum australe & 2.58 & Tremateia sp. 1 & \\
\hline
\end{tabular}

Studies that are independent of fungal isolation and identification methods often revealed higher numbers of fungal species [49]. We purposely chose the culture method to further select endophytic fungi of high interest according to their biological activities. Our goal was to yield a large number of endophytes, and not to produce a complete species list of fungal endophytes in these Artemisia species. Nevertheless, the data obtained gave us an interesting fragment of knowledge about the communities of these microorganisms in their plant hosts.

In terms of endophytic fungal species $\mathrm{CF} \%$, the most isolated species was Alternaria alternata ( $C F=18.71$; eight of ten plants), as expected. It is a common saprobe found on various plants and other substrata worldwide [50,51] and has often been isolated as endophyte in previous studies [52-55]. Qian et al., 2014 [27] isolated endophytic fungi from Artemisia argy and found Pleosporales to be the most represented group, with three species of Alternaria present. It was found as the most predominant species in grasses [56] and various plants families, also [57]. Among dominant endophytic fungal species, we observed taxa like Neofusicoccum and Preussia. These genera of endophytic fungi were previously isolated from a wide range of host plants including Artemisia spp. [24,57-60].

Interestingly, it was observed a tendency on host specificity of most endophytic fungal species. In Cirsium arvense similarity in endophytic communities decreased with increasing intersite distance [61] while in Holcus lanatus the similarity between leaf and root myco-assemblages at the same location was lower than that observed in leaves at different locations [58]. Further, in leaf fungal communities the average number of species shared by any pair of location was 3.13 and in root assemblages was 1.73 out of an average of 12.2 species identified at each location [58].

Despite the dominant species, the rest of the endophytic fungal species reflect an unequal distribution of a certain endophytic species among plant individuals. This same issue was previously observed [58] but no definitive answer has been found. Some hypotheses were proposed like ubiquitous taxa with spatial dominance or selection of certain dependent on culture conditions [58]. In the case study on Artemisia thuscula (see Section 3.1.3) taxa such as Preussia, Pestalotiopsis, Aplosporella, Chaetomium and Cladosporium were isolated from only one nutrient medium out of the three media 
tested. Nevertheless, this is not a unique parameter, which should account for the determination of an endophytic taxa preference for a nutrient medium. One of the major variables which we consider is the rest of the community involved and their role in the interaction when the isolation performed. That is, which are the other taxa living in the same "space" (i.e., plated plant fragment) and we must consider if there are (i) fast-growing taxa versus slow growing taxa; (ii) nutrient deficiency or promoting medium for certain taxa, as well as (iii) the interaction between the taxa (i.e. antagonism).

\subsubsection{Diversity Indices for Endophytic Fungi in Artemisia thuscula}

In the La Palma results of diversity, Margalef index revealed the highest value for species richness in San Bartolo (Margalef = 4.24) followed by El Granel (Margalef = 3.69). The Brillouin index agrees that the highest diversity is found in San Bartolo (Brillouin =1.8) but Fisher's alpha index shows a higher abundance of rare species in El Granel (Fisher's alpha $=18.6$ ) than in San Bartolo (Fisher's alpha $=13.9$ ). Diversity regarded as evenness was found to be similar in both localities (Simpson's index: El Granel $=0.88$ and San Bartolo = 0.87). In La Palma Island, San Bartolo locality was revealed as having the highest value for species richness and diversity. Yet, El Granel was shown as having a higher abundance of rare species (Fisher's alpha: El Granel $=18.6$ and San Bartolo $=13.9$ ) and a higher value of evenness than San Bartolo (Simpson's index: El Granel $=0.88$ and San Bartolo $=0.87$ ). In Tenerife, the locality San Andres showed by far the highest diversity in all previously mentioned terms and all the indices confirm it (Table 7).

Table 7. Diversity indices of fungal endophytic species per plant individual/locality.

\begin{tabular}{ccccccc}
\hline $\begin{array}{c}\text { Locality } \\
\text { Code }\end{array}$ & Taxa No. & Strains No. & $\begin{array}{c}\text { Simpson } \\
\text { 1-D }\end{array}$ & Brillouin & Margalef & $\begin{array}{c}\text { Fisher } \\
\text { Alpha }\end{array}$ \\
\hline LP1/EG & 11 & 15 & 0.89 & 1.65 & 3.69 & 18.60 \\
LP2/SB & 15 & 27 & 0.87 & 1.85 & 4.25 & 13.90 \\
LP4/TIG & 5 & 5 & 0.80 & 0.96 & 2.49 & 0.00 \\
TF1/MM & 5 & 10 & 0.60 & 0.85 & 1.74 & 3.98 \\
TF3/TA & 1 & 2 & 0.00 & 0.00 & 0.00 & 0.80 \\
TF4/IC & 2 & 3 & 0.44 & 0.37 & 0.91 & 2.62 \\
TF5/SA & 4 & 5 & 0.72 & 0.82 & 1.86 & 9.28 \\
TF7/GR & 3 & 3 & 0.67 & 0.60 & 1.82 & 0.00 \\
TF8/EP & 2 & 2 & 0.50 & 0.35 & 1.44 & 0.00 \\
\hline
\end{tabular}

LP1/EG = El Granel; LP2/SB = San Bartolo; LP4/TIG = Tigalate; TF1/MM = Mesa Mota; TF3/TA = Taborno; TF4/IC = Igueste Caletillas; TF5/SA = San Andres; TF7/GR = Granadilla; 14/EP = El Palmar.

Sorensen-Dice index revealed that of 45 cases in the matrix, 27 of them were of zero similarity. Further, only one case was found to have $57 \%$ similarity (TF2 versus TF7) and one case with $50 \%$ similarity (TF1 versus TF4). The rest of the cases had values ranging between $11 \%$ and $40 \%$ similarity. These different similarity values may be due to distance among hosts, soil composition and/or climatic conditions. When the distance was plotted (UPGMA), the Sorensen-Dice coefficient clustered plants LP1 and LP2 with maximum bootstrap support (BPP = 100), although these plants had only $38 \%$ similarity in between. Nevertheless, this is to be considered a high value of similarity in the given matrix and one of the reasons for obtaining it might be the proximity of the collection places (approx. $5 \mathrm{~km}$ ) between the host plants and similar altitudes and climate. Further clusters were formed like LP4 and TF1; TF2 and TF3; TF4, TF5 and TF7 (Figure 1). As we expected (from CF and CR values) TF8 is the most different host plant, the backbone of the dendrogram divides into this branch and the other branches which form various clusters of similarity. Also, cluster LP1 and LP2 is a sister cluster of the other clusters which were exhibited as more related in terms of similarity. 


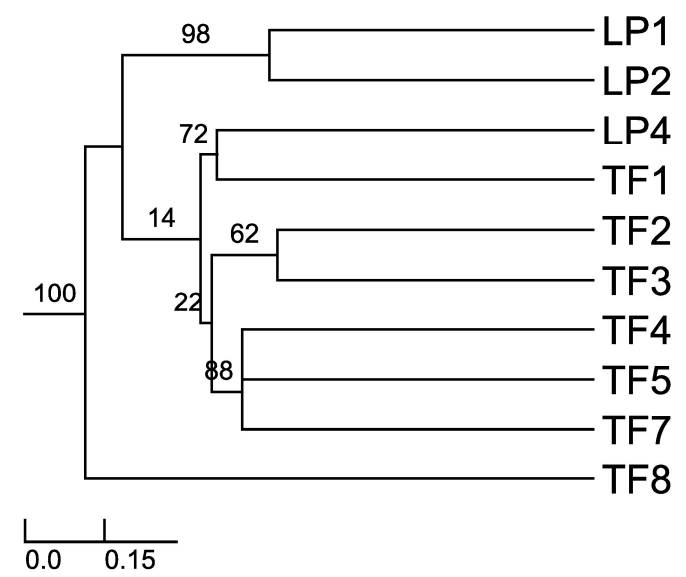

Figure 1. Sorensen's similarity coefficient for the endophytic fungi isolated from $A$. thuscula: unweighted paired group method of arithmetic average (UPGMA) dendrogram plot. The results were obtained with $95 \%$ of confidence and bootstrap values calculated from 1000 iterations.

3.1.3. Case Study: Artemisia thuscula of Tenerife, Endophytic Fungi Isolated from Two Types of Stems on Three Media: Colonization Frequency and Colonization Rate

In this study, we can observe throughout various individual plants from the same species (i.e., Artemisia thuscula) the relevance of nutrient media and the age of the stem as the selected organ to yield endophytic fungi. When averaged the colonization rates of the three nutrient media selected (PDA, LCA, and V8) do not show relevant differences $(C R \%=33.93 .33 .93$ and 37.50, respectively). Neither do the differences of age in stems; stems with the age $<1$ year have $C R \%=30.95$ and stems with age $>1$ year have $C R \%=36.90$.

Differences may be observed (Table 8) when comparing different plants, as for instance TF3 and TF4 had the lowest colonization rates $(\mathrm{CR} \%=16.67)$ and no endophytic fungi was isolated from $\mathrm{V} 8$ or stems with age of more than 1 year for TF4 and TF3, respectively. In addition, there is no higher value than 58.33 of colonization rate, as observed in other individuals of Artemisia.

Table 8. Artemisia thuscula colonization rate (CR\%) of endophytic fungi per plant. per medium and per stem age.

\begin{tabular}{|c|c|c|c|c|c|c|}
\hline \multirow{2}{*}{ Plant Code } & \multirow{2}{*}{ CR\%/Plant } & \multirow{2}{*}{ CR\%/PDA } & \multirow{2}{*}{ CR\%/LCA } & \multirow{2}{*}{$\mathrm{CR} \% / \mathrm{V} 8$} & \multicolumn{2}{|c|}{ CR\%/Stem } \\
\hline & & & & & Age $<1$ Year & Age $>1$ Year \\
\hline TF3 & 16.67 & 25 & 12.5 & 12.5 & 33.33 & 0 \\
\hline $\mathrm{TF} 4$ & 16.67 & 37.5 & 12.5 & 0 & 8.33 & 25 \\
\hline TF5 & 58.33 & 62.5 & 75 & 37.5 & 58.33 & 41.67 \\
\hline TF7 & 45.83 & 25 & 50 & 62.5 & 50 & 41.67 \\
\hline TF8 & 37.5 & 25 & 37.5 & 50 & 8.33 & 66.67 \\
\hline AVG & 35.12 & 33.93 & 33.93 & 37.50 & 30.95 & 36.90 \\
\hline
\end{tabular}

If colonization frequency data is segregated into plants sampled (Table 9), we observe that Alternaria alternata is the major colonizer in three out of seven plants, namely TF2, TF4, and TF5. Plants had different yields considering number of endophytic fungal species, ranging between three (TF3) and eight (TF7).

Among the major colonizers we observed Neofusicoccum austral and Neofusicoccum parvum in TF3 $($ CF\% = 8.33), Chaetomium sp. 1 and Phoma sp. 1 in TF7 and Phoma with two different species in TF8 (CF\% = 16.67; Table 8). Myrchiang et al., 2014 [28] investigated the endophytic fungi associated with Artemisia nilagirica and comparing the colonization of three organs (i.e., root, stem and leaf), the authors obtained the highest diversity in the roots (i.e., 14 species), less in stem (i.e., 10 species) and 
the smallest number in the leaves (i.e., 6 species). Similarly, in Artemisia thuscula Cosoveanu et al., 2012 [62] isolated 29 distinct morphotypes: 20 from roots, 7 from stem and 2 from leaves. In addition, Myrchiang et al., 2014 [28] observed that from all fungal endophytic species, only Phoma eupyrena was found to be a common occurrence in all plants sample, the other species having a certain preference for one or maximum two organs.

Table 9. Artemisia thuscula colonization frequency (CF\%) of endophytic fungi species per plant, per medium and per stem age.

\begin{tabular}{|c|c|c|c|c|c|c|c|}
\hline \multirow[t]{2}{*}{ EF Species } & \multirow[t]{2}{*}{ Plant } & \multirow[t]{2}{*}{ CF\%/Plant } & \multicolumn{3}{|c|}{ CF\%/Medium } & \multicolumn{2}{|c|}{ CF\%/Stem Age } \\
\hline & & & PDA & LCA & V8 & $\leq 1$ year old & $>1$ year old \\
\hline Alternaria alternata & \multirow{6}{*}{ TF2 } & 50 & 50 & 37.5 & 62.5 & 41.67 & 58.33 \\
\hline Alternaria sp. 4 & & 4.17 & & 12.5 & & & 8.33 \\
\hline $\begin{array}{l}\text { Biscogniauxia } \\
\text { mediterrranea }\end{array}$ & & 4.17 & 12.5 & & & 8.33 & \\
\hline Neofusicoccum australe & & 16.67 & 12.5 & 12.5 & 12.5 & 16.67 & 8.33 \\
\hline Pestalotiopsis sp. & & 4.17 & & 12.5 & & 8.33 & \\
\hline Phoma sp. 1 & & 4.17 & 12.5 & & & & 8.33 \\
\hline Neofusicoccum australe & \multirow{3}{*}{ TF3 } & 8.33 & 25 & & & 16.67 & \\
\hline Neofusicoccum parvum & & 8.33 & & 12.5 & 12.5 & 16.67 & \\
\hline Pestalotiopsis sp. & & 4.17 & & 12.5 & & 8.33 & \\
\hline Alternaria alternata & \multirow{3}{*}{ TF4 } & 12.5 & 37.5 & & & 16.67 & 8.33 \\
\hline Aureobasidium pullulans & & 4.17 & 12.5 & & & 8.33 & \\
\hline Nectria mauritiicola & & 8.33 & & 25 & & & 16.67 \\
\hline Alternaria alternata & \multirow{8}{*}{ TF5 } & 37.5 & 12.5 & 50 & 50 & 8.33 & 66.67 \\
\hline Alternaria sp. 6 & & 4.17 & 12.5 & & & 8.33 & \\
\hline Aplosporella prunicola & & 4.17 & & 12.5 & & 8.33 & \\
\hline Aureobasidium pullulans & & 4.17 & & 12.5 & & & 8.33 \\
\hline Macrophomina phaseolina & & 8.33 & 25 & & & & 16.67 \\
\hline Neofusicoccum australe & & 4.17 & & 12.5 & & 8.33 & \\
\hline Stachybotrys longispora & & 4.17 & 12.5 & & & 8.33 & \\
\hline Stemphylium solani & & 8.33 & & 12.5 & 12.5 & 16.67 & \\
\hline Alternaria alternata & \multirow{8}{*}{ TF7 } & 8.33 & 8.33 & 12.5 & 12.5 & & 16.67 \\
\hline Aureobasidium pullulans & & 12.5 & & 12.5 & & 8.33 & \multirow{3}{*}{16.67} \\
\hline Chaetomium sp. 1 & & 16.67 & & \multirow{6}{*}{50} & 25 & & \\
\hline Cladosporium sp. 1 & & 12.5 & & & 25 & 16.67 & \\
\hline Neofusicoccum australe & & 8.33 & & & 12.5 & & \multirow[t]{2}{*}{8.33} \\
\hline Phoma sp. 1 & & 16.67 & & & & 33.33 & \\
\hline Preussia australis & & 8.33 & 12.5 & & & & \multirow[t]{2}{*}{8.33} \\
\hline Stemphylium solani & & 4.17 & 12.5 & & & 8.33 & \\
\hline $\begin{array}{l}\text { Biscogniauxia } \\
\text { mediterrranea }\end{array}$ & \multirow{7}{*}{ TF8 } & 8.33 & & & 12.5 & \multirow{7}{*}{8.33} & 8.33 \\
\hline Camarosporium sp. 1 & & 8.33 & 12.5 & & & & 8.33 \\
\hline Phoma sp. 1 & & 16.67 & 12.5 & & & & \\
\hline Preussia sp. 2 & & 16.67 & & & 37.5 & & 25 \\
\hline Preussia sp. 3 & & 12.5 & & 12.5 & & & 8.33 \\
\hline Preussia sp. 5 & & 12.5 & & 25 & & & 16.67 \\
\hline Stemphylium solani & & 4.17 & & 12.5 & & & 8.33 \\
\hline
\end{tabular}

Comparing different plant individuals of the same species and observing the distribution of fungal endophytes provides insights to determine the occurrence of a certain species. For instance, in TF2 four fungal species were isolated only from one nutrient medium, namely Biscogniauxia mediterranea in PDA, Alternaria sp. on LCA, Phoma sp. on PDA and Pestalotiopsis sp. on LCA (Table 9). Furthermore, we may observe that the same species of Phoma sp. 1 was also isolated from TF8 on PDA, similar to Pestalotiopsis isolated from TF3 on LCA while Biscogniauxia mediterranea was isolated on V8 from TF8.

When the distribution of endophytic fungi species is observed in terms of colonization frequency per total number of the studied plants (Figure 2), data showed several species like Aplosporella prunicola, Camarosporium sp., Chaetomium sp., Cladosporium sp, Nectria mauritiicola and others with certain "preference" for nutrient medium. It is well known that fungi have specific carbon and nitrogen requirements for sporulation [63-65]. However, the requirements for fungal growth are less stringent but not less important when isolation is pursued. Nutrient - rich media result in selective isolation for fast-growing fungi, overlooking slow growing species if present [66]. Osono and Takeda [29] stated 
that LCA due to its low glucose content suppresses the overgrowth of fast-growing species. 22 species of fungal endophytes were isolated from all Artemisia thuscula plants in this case study and 14 species $(63 \%)$ were isolated only from one nutrient medium. Additionally, 12 fungal species were isolated from stems older than 1 year and seven were isolated from stems younger than one year. Seven fungal species are to be considered rare, as their colonization frequency value is the lowest one, throughout the data set $(\mathrm{CF} \%=0.60$; Figure 2$)$.

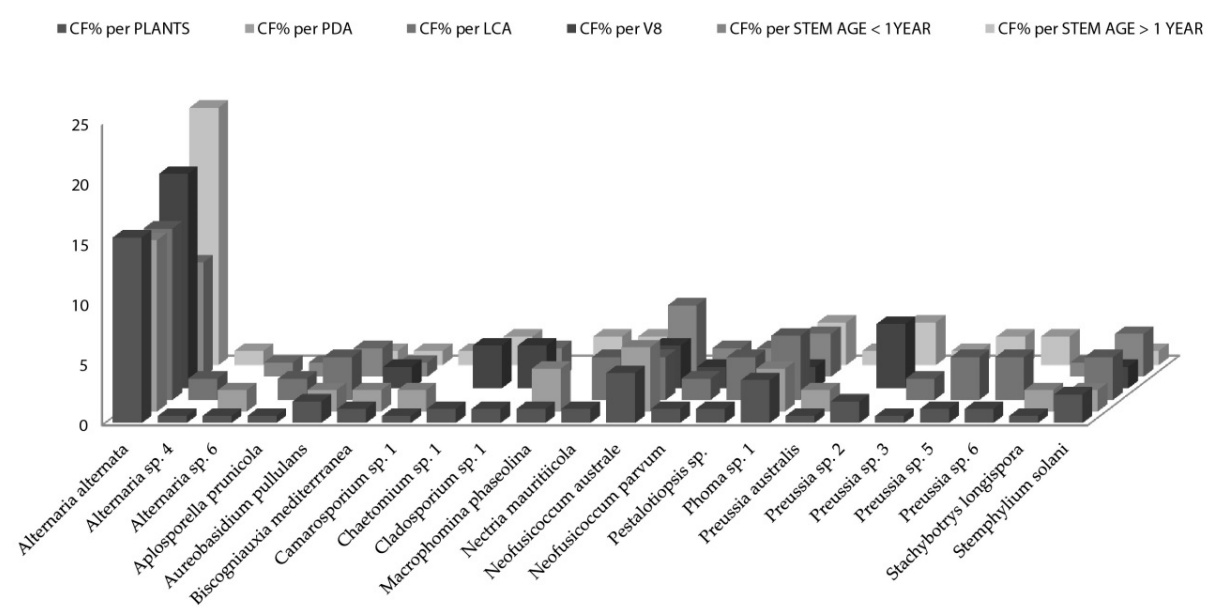

Figure 2. Artemisia thuscula colonization frequencies of endophytic fungi species per total number of plant individuals, per media (PDA, lignocellulose agar (LCA) and V8) and per stem age (>1 year and $<1$ year). The $y$-axis data correspond to colonization frequency percentage.

Further, Sorensen-Dice similarity coefficient reveals proximate values among the similarities of the endophytic communities isolated on the three tested media (Table 10). Yet, none of them overpassed $52 \%$ similarity (i.e., LCA versus V8). As for the stem ages, the index showed a value of $43 \%$ similarity. Evidence for tissue specificity was previously demonstrated for phloem and xylem tissue, where the value of endophytic similarity reached $36 \%$ in roots of Sophora tonkinensis [67]. This suggests the necessity to broad both culture media and diversity of tissues to obtain a higher richness of endophytic fungal taxa.

Table 10. A. thuscula fungal endophytes isolated on different nutrient media and stem age: Sorensen-Dice coefficient of similarity.

\begin{tabular}{ccccc}
\hline & LCA & V8 & $\leq \mathbf{1}$ Year & $>$ 1 Year \\
\hline PDA & 0.42 & 0.48 & 0.64 & 0.71 \\
LCA & & 0.52 & 0.67 & 0.67 \\
V8 & & & 0.67 & 0.59 \\
$\leq 1$ year & & & & 0.43 \\
\hline
\end{tabular}

Among the singleton species that occur only in the Artemisia thuscula plant individuals selected for this case study (i.e., limited to Tenerife) we have: Aplosporella prunicola, Camarosporium sp. 1, Macrophomina phaseolina, Chaetomium sp. 1, Nectria mauritiicola, Neofusicoccum australe, Pestalotiopsis sp., Phoma sp. 1 and Stachybotrys longispora. Except Phoma sp., all endophytic fungal species previously mentioned were isolated from only one nutrient medium. In addition, except Camarosporium sp. (isolated also from Artemisia thuscula in Palma Island), all endophytic fungal species previously named were isolated only from Artemisia thuscula in Tenerife Island.

\subsection{Phylogenetic Relations}

54 endophytic fungal ITS sequences and the associated GenBank sequences were used for the phylogenetic analysis (Table 3; sequences of strains HLP16, HLP22, HLP28, HLP33, HLP48A, HLP4, 
HTF29, HTF33, HTF43, and HTF61 are not listed and are only available at request). The dataset consists of 603 characters after alignment, 43 characters are conserved, and 447 characters are parsimony informative, while 557 are variable characters. Bayesian Posterior Probabilities (BPPs) given below each node are shown on the upper branches.

Ten orders (Diaporthales, Dothideales, Botryosphaeriales, Hypocreales, Trichosphaeriales, Amphisphaeriales, Xylariales, Capnodiales, Pleosporales and Eurotiales) are recognized (Figure 3). The phylogenetic tree divides the taxa in five main clades, leaving Diaporthe sequences unclustered. Clade 1 consists of Dothideales and Botryosphaeriales (BPP $=0.98)$, Clade 2 groups Hypocreales, Trichosphaeriales, Amphisphaeriales and Xylariales (BPP $=0.88)$, Clade 3 and Clade 4 contain Capnodiales $(\mathrm{BPP}=0.79)$ and Pleosporales $(\mathrm{BPP}=0.63)$, respectively while Clade 5 accommodates Eurotiales $(\mathrm{BPP}=0.62)$.

Interestingly, Diaporthe sequences are not clustered but several show different branch lengths. Yet, taxa $D$. novem and $D$. phaseolorum do not differentiate. Endophytic fungi were basically identified using morphology; therefore, HLP15 and HLP23 were considered D. phaseolorum and D. novem, respectively while structures of HLP37 did not allow an accurate species level identification. Apparently, the ITS region in Diaporthe is evolving at higher rates than TEF1 or MAT genes [68], therefore presenting a wider variation than advisable for species boundaries. Thus, a slowly evolving gene region should be used in order to establish species limits [69]. Nevertheless, ITS sequence data can be used for reliable identification of phylogenetic relationships as long as they are interpreted with care [69]. Several arrangements of genera draw the attention, like Aureobasidium (Dothideales) and Aplosporella (Botryosphaeriales) which are shown with an immediate common ancestor (BPP $=0.97$ ). Aplosporella has over 300 species and appears to be heterogenous; therefore not all species are likely to belong in Botryosphaeriaceae [70]. The ascomycete genus Aureobasidium is a member of the family Aureobasidiaceae within the class of the Dothideomycetes [71]. Dothideomycetidae subclass was emended by Schoch et al., 2006 [72] and a new subclass was proposed, Pleosporomycetidae, with an additional order, the Botryosphariales.

Penicillium and Aspergillus sequences form two sister clades as expected (BPP $=0.60)$. Three species of Neofusicoccum are clustered with relevant support $(\mathrm{BPP}=0.89)$ while N. parvum is drawn outside. Hypocreales taxa are split in two sister clusters along with Stachybotrys, Grandibotrys, Melanopsamma and Sirastachys in one sister clade although with no relevant support (BPP $=0.55)$ and Nectria, Sarocladium and Corallomycetela as another sister clade (BPP $=0.87)$. Also, internal clustering is revealed between several taxa of the mentioned genera. Trichosphaeriales and Amphisphaeriales are shown having a common recent ancestor (BPP $=0.98)$. Hypocreales is recognized as monophyletic [73]. The order Hypocreales incorporates Nectriaceae and Stachybotriaceae beyond other six families [74]. Maharachchikumbura et al., 2014 [75] found using a combined LSU, SSU, TEF and RPB2 sequences data that Stachybotrys and related taxa (Stachybotriaceae) form a sister cluster of Nectria and related taxa (Nectriaceae). The results obtained with the ITS region are in accordance with the combined inference obtained by Maharachchikumbura et al., [75]. The Nectriaceae group (BPP $=0.87$ ) comprises Nectria (Nectriaceae), Sarocladium (Hypocreomycetidae) and Corallomycetella - shown to comprise two distinct clades in Nectriaceae [76]. The second cluster joints Stachybotrys, Grandibotrys, Sirastachys, Stachybotrys (Stachybotriaceae, Hypocreomycetidae) and Melanopsamma (Chaetosphaeriaceae, Sordariomycetidae). Melanopsamma pomiformis was recently excluded from the genus [77] and it was linked to the asexual morph Stachybotrys albipes [78]. Strains of Sordariomycetes clustered into six subclasses among which Diaporthomycetidae, Xylariomycetidae and Hypocreomycetidae [75]. Our Bayesian analysis resulted in a monophyletic clade (Clade 2) which accommodates Hypocreales (Hypocreomycetidae), Trichosphaeriales (Diaporthomycetidae), Amphisphaeriales (Xylariomycetidae) and Xylariales (Xylariomycetidae). Yet, Diaporthales taxa (Diaporthe spp.) were left outside this clade. A resulting parsimonious tree of multi-locus based (LSU, ITS, and TEF1) sequences shows that the genus Diaporthe has paraphyletic origins [79]. Xylariales and Amphisphaeriales were found as sister clusters in Xylariomycetidae sharing a common ancestor [80]. 
Yet, the clade which accommodates Xylariomycetidae is a sister clade of Diaporthomycetidae (Diaporthales) and Hypocreomycetidae (Hypocreales).

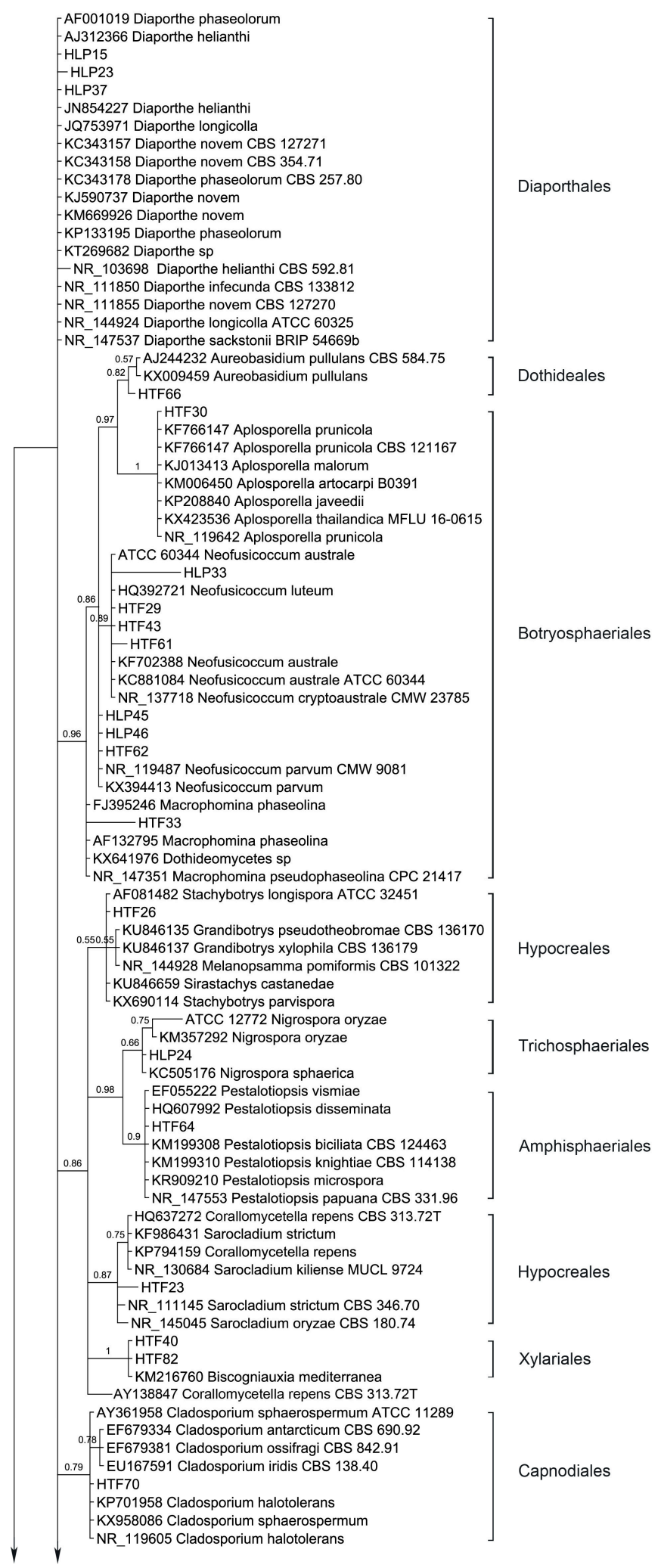

Figure 3. Cont. 


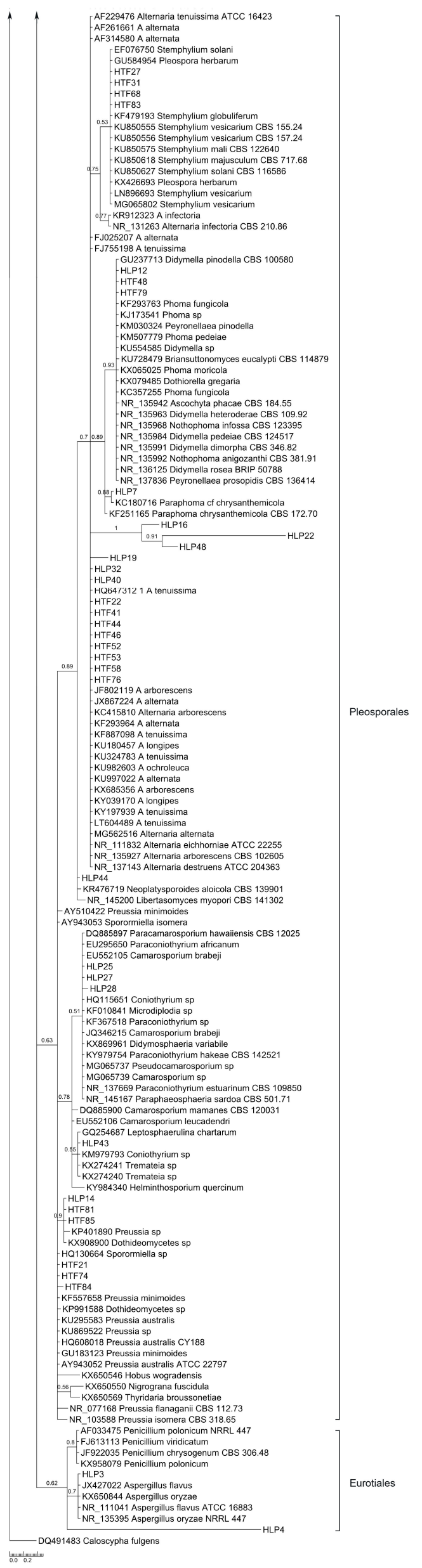


Figure 3. Bayesian phylogenetic tree based on ITS rDNA sequence variants of the endophytic fungi isolated from A. thuscula and their associated external GenBank hits. The tree was rooted with Caloscypha fulgens sequence as outgroup. The Bayesian clade-credibility values (posterior probabilities) are indicated at internodes (BPP). The scale bar represents the expected changes per site. Sequences coded with HLP/HTF were obtained from endophytic fungi, sequences coded with taxa names are associated external sequences and the ones coded with CBS/L/ATCC/NRRL/B/MFLU/CMW/MUCL/BRIP were obtained from type strains.

Cladosporium sequences are clustered $(\mathrm{BPP}=0.79)$ and different branch lengths between species are revealed, grouping C. ossifragi, C. antarcticum and C. iridis ( $\mathrm{BPP}=0.78)$. Conversely, Aplosporella sequences do not differentiate in between, showing all species with same branch lengths.

Stemphylium sequences are grouped but support does not avail this grouping (BPP $=0.53$ ). Phoma-like sequences are clustered as expected $(\mathrm{BPP}=0.93)$ showing higher differences between Phoma, Didymella, Dothiorella and Notophoma on one side (BPP = 0.93) and Paraphoma chrysantemicola on the other side (BPP $=0.88)$. It is curious that several sequences of endophytes are grouped in a sister clade of Alternaria clade, Phoma-like clade and Stemphylium clade with high probability (BPP =1), indicating different branch lengths. Alternaria sequences are not grouped in a single cluster but different branch lengths are drawn among the species. Similarly, Preussia and Sporormiella taxa are spread. Coniothyrium-like sequences are clustered, but support has an average value, $\mathrm{BPP}=0.78$. Coniothyriaceae and Camarosporiaceae grouping as well as the Coniothyrium-like sequences cluster and its sister cluster of Pleosporaceae is supported by the findings of Wijayawardene et al., 2014 [81]. Mainly the sequences obtained from the endophytic strains are grouped with the external sequences as expected (i.e., morphological identification) but several are left unclustered. For instance, inside the group of Pleosporales three endophytic sequences (HLP16, HLP22 and HLP48A) appear as more related, forming a strong-supported cluster $(\mathrm{BPP}=1)$. This apparently new lineage should be confirmed with another phylogenetic study based on large subunit and small subunit nuclear rDNA regions, where only Pleosporales taxa would be included. In the present study none of the methods used like the morphology (absence of the sporulating structures), BLAST alignment (values of similarity with GenBank provided sequences did not exceed 86\%, 88\% and 84\% for HLP16, HLP22, and HLP48A, respectively) and the ITS inference, could provide their proper identification or genetic stronger alliances inside Pleosporales.

\section{Conclusions}

The present study suggests culturable endophytic species have specificity for a plant host and "preference" for nutrient medium. Therefore, this study indicates the apparent necessity of using different culture media so as to obtain a higher diversity of species.

Acknowledgments: We thank Kanika Chowdhary (Indian Institute of Technology) and Mariano Hernandez (Dept. Bioquimica, Microbiologia, Biologia Celular y Genetica, Universidad of La Laguna) for their valuable contributions. Two anonymous reviewers are thanked for their comments and suggestions on the draft version of this script. The authors are grateful to Cristian Predescu and Alin Gayraud for the graphical elements - phylogenetic tree and abstract, respectively. Andreea Cosoveanu was supported by the pre-doc contract as research personnel in formation (sp. "Contratos predoctorales para la formación de doctores"), Call 2015 by Universidad de La Laguna and La Caixa.

Author Contributions: Andreea Cosoveanu and Raimundo Cabrera conceived and designed the experiments; Andreea Cosoveanu and Samuel Rodriguez Sabina performed the experiments; Andreea Cosoveanu and Raimundo Cabrera analyzed the data; Raimundo Cabrera contributed reagents/materials/analysis tools; Andreea Cosoveanu and Raimundo Cabrera wrote the paper.

Conflicts of Interest: The authors declare no conflict of interest. The founding sponsors had no role in the design of the study; in the collection, analyses, or interpretation of data; in the writing of the manuscript, and in the decision to publish the results. 


\section{References}

1. Arnold, A.E.; Maynard, Z.; Gilbert, G.; Coley, P.; Kursar, T. Are Tropical Fungal Endoyphytes Hyperdiverse? Ecol. Lett. 2000, 3, 267-274. [CrossRef]

2. Sturz, A.V.; Christie, B.R.; Nowak, J. Critical Reviews in Plant Sciences Bacterial Endophytes: Potential Role in Developing Sustainable Systems of Crop Production. CRC Crit. Rev. Plant Sci. 2000, 19, 1-30. [CrossRef]

3. Smith, C.S.; Chand, T.; Harris, R.F.; Andrews, J.H. Colonization of a Submersed Aquatic Plant, Eurasian Water Milfoil (Myriophyllum spicatum), by Fungi under Controlled Conditions. Appl. Environ. Microbiol. 1989, 55, 2326-2332. [PubMed]

4. Stanley, S.J. Observations on the Seasonal Occurrence of Marine Endophytic and Parasitic Fungi. Can. J. Bot. 1992, 70, 2089-2096. [CrossRef]

5. Petrini, O.; Fisher, P.J.; Petrini, L.E. Fungal Endophyte of Bracken (Pteridium aquilinum) with Some Reflections on Their Use in Biological Control. Sydowia 1992, 44, 282-293.

6. Raviraja, N.S.; Sridhar, K.R.; Barlocher, F. Endophytic Aquatic Hyphomycetes of Roots of Plantation Crops and Ferns from India. Sydowia 1996, 48, 152-160.

7. Nisa, H.; Kamili, A.N.; Nawchoo, I.A.; Shafi, S.; Shameem, N.; Bandh, S.A. Fungal Endophytes as Prolific Source of Phytochemicals and Other Bioactive Natural Products: A Review. Microb. Pathog. 2015, 82, 50-59. [CrossRef] [PubMed]

8. Pirttilä, A.M.; Laukkanen, H.; Pospiech, H. Detection of Intracellular Bacteria in the Buds of Scotch Pine (Pinus sylvestris L.) by In Situ Hybridization. Appl. Environ. Microbiol. 2000, 66, 3073-3077. [CrossRef] [PubMed]

9. Pirttilä, A.M.; Pospiech, H.; Laukkanen, H.; Myllylä, R.; Hohtola, A. Two Endophytic Fungi in Different Tissues of Scots Pine Buds (Pinus sylvestris L.). Microb. Ecol. 2003, 45, 53-62. [CrossRef] [PubMed]

10. Hata, K.; Sone, K. Isolation of Endophytes from Leaves of Neolitsea sericea in Broadleaf and Conifer Stands. Mycoscience 2008, 49, 229-232. [CrossRef]

11. Pirttilä, A.M.; Podolich, O.; Koskimäki, J.J.; Hohtola, E.; Hohtola, A. Role of Origin and Endophyte Infection in Browning of Bud-Derived Tissue Cultures of Scots Pine (Pinus sylvestris L.). Plant Cell Tissue Organ Cult. 2008, 95, 47-55. [CrossRef]

12. Panaccione, D.G.; Beaulieu, W.T.; Cook, D. Bioactive Alkaloids in Vertically Transmitted Fungal Endophytes. Funct. Ecol. 2014, 28, 299-314. [CrossRef]

13. Porras-Alfaro, A.; Herrera, J.; Sinsabaugh, R.L.; Odenbach, K.J.; Lowrey, T.; Natvig, D.O. Novel Root Fungal Consortium Associated with a Dominant Desert Grass. Appl. Environ. Microbiol. 2008, 74, 2805-2813. [CrossRef] [PubMed]

14. Maciá-Vicente, J.G.; Ferraro, V.; Burruano, S.; Lopez-Llorca, L.V. Fungal Assemblages Associated with Roots of Halophytic and Non-Halophytic Plant Species Vary Differentially Along a Salinity Gradient. Microb. Ecol. 2012, 64, 668-679. [CrossRef] [PubMed]

15. Ernst, M.; Mendgen, K.W.; Wirsel, S.G.R. Endophytic Fungal Mutualists: Seed-Borne Stagonospora spp. Enhance Reed Biomass Production in Axenic Microcosms. Mol. Plant-Microbe Interact. 2003, 16, $580-587$. [CrossRef] [PubMed]

16. Rodriguez, R.; Freeman, D. Symbiotic Regulation of Plant Growth, Development and Reproduction. Commun. Integr. Biol. 2009, 2, 141-143. [CrossRef] [PubMed]

17. Kusari, S.; Lamshoft, M.; Zühlke, S.; Spiteller, M. An Endophytic Fungus from Hypericum perforatum That Produces Hypericin. J. Nat. Prod. 2008, 71, 159-162. [CrossRef] [PubMed]

18. Stierle, A.; Strobel, G.; Stierle, D. Taxol and Taxane Production by Taxomyces andreanae, an Endophytic Fungus of Pacific Yew. Science 1993, 260, 214-216. [CrossRef] [PubMed]

19. Stierle, D.B.; Stierle, A.A.; Bugni, T. Sequoiamonascins A-D: Novel Anticancer Metabolites Isolated from a Redwood Endophyte. J. Org. Chem. 2003, 68, 4966-4969. [CrossRef] [PubMed]

20. Shu, S.; Zhao, X.; Wang, W.; Zhang, G.; Cosoveanu, A.; Ahn, Y.; Wang, M. Identification of a Novel Endophytic Fungus from Huperzia serrata Which Produces Huperzine A. World J. Microbiol. Biotechnol. 2014, 30, 3101-3109. [CrossRef] [PubMed]

21. Schulz, B.; Boyle, C. The Endophytic Continuum. Mycol. Res. 1998, 109, 661-686. [CrossRef] 
22. Gashgari, R.; Gherbawy, Y.; Ameen, F.; Alsharari, S. Molecular Characterization and Analysis of Antimicrobial Activity of Endophytic Fungi from Medicinal Plants in Saudi Arabia. Jundishapur J. Microbiol. 2016, 9, 1-8. [CrossRef] [PubMed]

23. Cosoveanu, A.; Hernandez, M.; Iacomi-Vasilescu, B.; Zhang, X.; Shu, S.; Wang, M.; Cabrera, R. Fungi as Endophytes in Chinese Artemisia spp.: Juxtaposed Elements of Phylogeny, Diversity and Bioactivity. Mycosphere 2016, 7, 102-117. [CrossRef]

24. Huang, W.Y.; Cai, Y.Z.; Surveswaran, S.; Hyde, K.D.; Corke, H.; Sun, M. Molecular Phylogenetic Identification of Endophytic Fungi Isolated from Three Artemisia Species. Fungal Divers. 2009, 36, 69-88.

25. Qadri, M.; Johri, S.; Shah, B.A.; Khajuria, A.; Sidiq, T.; Lattoo, S.K.; Abdin, M.Z.; Riyaz-Ul-Hassan, S. Identification and Bioactive Potential of Endophytic Fungi Isolated from Selected Plants of the Western Himalayas. SpringerPlus 2013, 2, 8. [CrossRef] [PubMed]

26. Yuan, Z.L.; Chen, Y.C.; Ma, X.J. Symbiotic Fungi in Roots of Artemisia annua with Special Reference to Endophytic Colonizers. Plant Biosyst. 2011, 145, 495-502. [CrossRef]

27. Qian, Y.; Kang, J.; Geng, K.; Wang, L.; Lei, B. Endophytic Fungi from Artemisia argyi Levl. et Vant. and Their Bioactivity. Chiang Mai J. Sci. 2014, 41, 910-921.

28. Myrchiang, P.; Dkhar, M.S.; Devi, H.R. Studies on Endophytic Fungi Associated with Medicinally Important Aromatic Plant Artemisia nilagirica (C.B. Clarke) Pamp. and Their Antagonistic Activity against Phytophthora infestans. J. Adv. Lab. Res. Biol. 2014, 5, 112-119.

29. Osono, T.; Ishii, Y.; Takeda, H.; Seramethakun, T.; Khamyong, S.; To-Anun, C.; Hirose, D.; Tokumasu, S.; Kakishima, M. Fungal Succession and Lignin Decomposition on Shorea obtusa Leaves in a Tropical Seasonal Forest in Northern Thailand. Fungal Divers. 2009, 36, 101-119.

30. White, T.J.; Bruns, T.; Lee, S.; Taylor, J. Amplification and Direct Sequencing of Fungal Ribosomal RNA Genes for Phylogenetics. In PCR Protocols: A Guide to Methods and Applications; Innis, M.A., Gelfand, D.H., Sninsky, J.J., White, T.J., Eds.; Academic Press, Inc.: New York, NY, USA, 1990; pp. 315-322.

31. O'Donnell, K. Fusarium and Its near Relatives. In The Fungal Holomorph: Mitotic, Meiotic and Pleomorphic Speciation in Fungal Systematics; Reynolds, R., Taylor, J.W., Eds.; CBA International: Wallingford, UK, 1993; pp. 225-233.

32. Thompson, J.D.; Higgins, D.G.; Gibson, T.J. CLUSTAL W: Improving the Sensitivity of Progressive Multiple Sequence Alignment through Sequence Weighting, Position-Specific Gap Penalties and Weight Matrix Choice. Nucleic Acids Res. 1994, 22, 4673-4680. [CrossRef] [PubMed]

33. Tamura, K.; Stecher, G.; Peterson, D.; Filipski, A.; Kumar, S. MEGA6: Molecular Evolutionary Genetics Analysis Version 6.0. Mol. Biol. Evol. 2013, 30, 2725-2729. [CrossRef] [PubMed]

34. Foronda, P.; López-González, M.; Hernández, M.; Haukisalmi, V.; Feliu, C. Distribution and Genetic Variation of Hymenolepidid cestodes in Murid Rodents on the Canary Islands (Spain). Parasit. Vectors 2011, 4, 185. [CrossRef] [PubMed]

35. Simmons, M.P.; Ochoterena, H. Gaps as Characters in Sequence-Based Phylogenetic Analyses. Syst. Biol. 2000, 49, 369-381. [CrossRef] [PubMed]

36. Borchsenius, F. FastGap, version 1.2; Department of Biosciences, Aarhus University: Aarhus, Denmark, 2009.

37. Dereeper, A.; Guignon, V.; Blanc, G.; Audic, S.; Buffet, S.; Chevenet, F.; Dufayard, J.-F.; Guindon, S.; Lefort, V.; Lescot, M.; et al. Phylogeny.fr: Robust Phylogenetic Analysis for the Non-Specialist. Nucleic Acids Res. 2008, 36, W465-W469. [CrossRef] [PubMed]

38. Darriba, D.; Taboada, G.L.; Doallo, R.; Posada, D. jModelTest 2: More Models, New Heuristics and Parallel Computing. Nat. Methods 2012, 9, 772. [CrossRef] [PubMed]

39. Huelsenbeck, J.P.; Ronquist, F. MRBAYES: Bayesian Inference of Phylogenetic Trees. Bioinformatics 2001, 17, 754-755. [CrossRef] [PubMed]

40. Ramírez-Bahena, M.H.; Hernández, M.; Peix, A.; Velázquez, E.; León-Barrios, M. Mesorhizobial Strains Nodulating Anagyris latifolia and Lotus berthelotii in Tamadaya Ravine (Tenerife, Canary Islands) Are Two Symbiovars of the Same Species, Mesorhizobium tamadayense sp. nov. Syst. Appl. Microbiol. 2012, 35, 334-341. [CrossRef] [PubMed]

41. Stöver, B.C.; Müller, K.F. TreeGraph 2: Combining and Visualizing Evidence from Different Phylogenetic Analyses. BMC Bioinform. 2010, 11, 7. [CrossRef] [PubMed]

42. Margalef, R.D. Information Theory In Ecology. Gen. Syst. 1958, 3, 36-71.

43. Pielou, E.C. An Introduction to Mathematical Ecology; Wiley-Interscience: New York, NY, USA, 1969. 
44. Pielou, E.C. Ecological Diversity; Wiley: New York, NY, USA, 1975.

45. Fisher, R.A.; Corbet, S.A.; Williams, C.B. The Relation between the Number of Species and the Number of Individuals in a Random Sample of an Animal Population. J. Anim. Ecol. 1943, 12, 42-58. [CrossRef]

46. Simpson, E.H. Measurement of Diversity. Nature 1949, 163, 688. [CrossRef]

47. Sorensen, T. A Method of Establishing Groups of Equal Amplitude in Plant Sociology Based on Similarity of Species Content and Its Application to Analyses of the Vegetation on Danish Commons; I kommission hos E. Munksgaard: København, Danmark, 1948.

48. Dice, L. Measures of the Amount of Ecologic Association Between Species. Ecology 1945, 26, $297-302$. [CrossRef]

49. Arnold, A.E. Understanding the Diversity of Foliar Endophytic Fungi: Progress, Challenges, and Frontiers. Fungal Biol. Rev. 2007, 21, 51-66. [CrossRef]

50. Grunden, E.; Chen, W.D.; Crane, J.L. Fungi Colonizing Microsclerotia of Verticillium dahliae in Urban Environments. Fungal Divers. 2001, 8, 129-141.

51. Tokumasu, S.; Aoiki, T. A New Approach to Studying Microfungal Succession on Decaying Pine Needles in an Oceanic Subtropical Region in Japan. Fungal Divers. 2002, 10, 167-183.

52. Guo, L.; Xu, L.; Zheng, W.; Hyde, K.D. Genetic Variation of Alternaria alternata, an Endophytic Fungus Isolated from Pinus tabulaeformis as Determined by Random Amplified Microsatellites (RAMS). Fungal Divers. 2004, 16, 53-67.

53. Kumaresan, V.; Suryanarayanan, T.S. Endophyte Assemblages in Young, Mature and Senescent Leaves of Rhizophora apiculata: Evidence for the Role of Endophytes in Mangrove Litter Degradation. Fungal Divers. 2002, 9, 81-91.

54. Taylor, J.E.; Hyde, K.D.; Jones, E.B.G. Endophytic fungi associated with the temperate palm, Trachycarpus fortunei, within and outside its natural geographic range. New Phytol. 1999, 142, 335-346. [CrossRef]

55. Romero, A.; Carrion, G.; Rico-Gray, V. Fungal Latent Pathogens and Endophytes. Fungal Divers. 2001, 7, $81-87$.

56. Wearn, J.A.; Sutton, B.C.; Morley, N.J.; Gange, A.C. Species and Organ Specificity of Fungal Endophytes in Herbaceous Grassland Plants. J. Ecol. 2012, 100, 1085-1092. [CrossRef]

57. Sun, Y.; Wang, Q.; Lu, X.; Okane, I.; Kakishima, M. Endophytic Fungal Community in Stems and Leaves of Plants from Desert Areas in China. Mycol. Prog. 2012, 11, 781-790. [CrossRef]

58. Sánchez Márquez, S.; Bills, G.F.; Acuña, L.D.; Zabalgogeazcoa, I. Endophytic Mycobiota of Leaves and Roots of the Grass Holcus lanatus. Fungal Divers. 2010, 41, 115-123. [CrossRef]

59. Cannon, P.F.; Simmons, C.M. Diversity and Host Preference of Leaf Endophytic Fungi in the Iwokrama Forest Reserve, Guyana. Mycologia 2002, 94, 210-220. [CrossRef] [PubMed]

60. Rodriguez, R.J.; White, J.F.; Arnold, A.E.; Redman, R.S. Fungal Endophytes: Diversity and Functional Roles. New Phytol. 2009, 182, 314-330. [CrossRef] [PubMed]

61. Gange, A.C.; Dey, S.; Currie, A.F.; Sutton, B.C. Site- and species-specific differences in endophyte occurrence in two herbaceous plants. J. Ecol. 2007, 95, 614-622. [CrossRef]

62. Cosoveanu, A.; Da Silva, E.; Gimenez Marino, C.; Nunez Trujillo, G.; Gonzales Coloma, A.; Frias Viera, I.; Cabrera, R. Artemisia thuscula Cav.: Antibacterial, Antifungal Activity of the Plant Extracts and Associated Endophytes. J. Hortic. For. Biotechnol. 2012, 16, 87-90.

63. Su, Y.-Y.; Qi, Y.-L.; Cai, L. Induction of Sporulation in Plant Pathogenic Fungi Induction of Sporulation in Plant Pathogenic Fungi. Mycology 2012, 33, 195-200. [CrossRef]

64. Sharma, G.; Pandey, R.R. Influence of Culture Media on Growth, Colony Character and Sporulation of Fungi Isolated from Decaying Vegetable Wastes. J. Yeast Fungal Res. 2010, 1, 157-164.

65. Kumara, K.W.; Rawal, R.D. Influence of Carbon, Nitrogen, Temperature and pH on the Growth and Sporulation of Some Indian Isolates of Colletotrichum gloeosporioides Causing Anthracnose Disease of Papaya (Carrica papaya L.). Trop. Agric. Res. Ext. 2008, 11, 7-12. [CrossRef]

66. Osono, T. Fungal Decomposition of Leaf Litter in a Cool Temperate Forest; Kyoto University: Kyoto, Japan, 2002.

67. Yao, Y.Q.; Lan, F.; Qiao, Y.M.; Wei, J.G.; Huang, R.S.; Li, L.B. Endophytic Fungi Harbored in the Root of Sophora tonkinensis Gapnep: Diversity and Biocontrol Potential against Phytopathogens. MicrobiologyOpen 2017, 6. [CrossRef] [PubMed] 
68. Santos, J.M.; Correia, V.G.; Phillips, A.J.L. Primers for Mating-Type Diagnosis in Diaporthe and Phomopsis: Their Use in Teleomorph Induction in Vitro and Biological Species Definition. Fungal Biol. 2010, 114, 255-270. [CrossRef] [PubMed]

69. Udayanga, D.; Liu, X.; McKenzie, E.H.C.; Chukeatirote, E.; Bahkali, A.H.A.; Hyde, K.D. The Genus Phomopsis: Biology, Applications, Species Concepts and Names of Common Phytopathogens. Fungal Divers. 2011, 50, 189-225. [CrossRef]

70. Hyde, K.D.; Mckenzie, E.H.C.; KoKo, T.W. Towards Incorporating Anamorphic Fungi in a Natural Classification-checklist and Notes for 2011. Mycosphere 2012, 3, 157-228. [CrossRef]

71. Thambugala, K.M.; Ariyawansa, H.A.; Li, Y.-M.; Boonmee, S.; Hongsanan, S.; Tian, Q.; Singtripop, C.; Bhat, D.J.; Camporesi, E.; Jayawardena, R.; et al. Dothideales. Fungal Divers. 2014, 68, 105-158. [CrossRef]

72. Schoch, C.L.; Shoemaker, R.A.; Seifert, K.A.; Hambleton, S.; Spatafora, J.W.; Crous, P.W. A Multigene Phylogeny of the Dothideomycetes Using Four Nuclear Loci. Mycologia 2006, 98, 1041-1052. [CrossRef] [PubMed]

73. Eriksson, O.E. Outline of Ascomycota-2006. Myconet 2006, 12, 1-82.

74. Eriksson, O.E.; Winka, K. Supraordinal Taxa of Ascomycota. Myconet 1997, 1, 1-16.

75. Maharachchikumbura, S.S.N.; Hyde, K.D.; Jones, E.B.G.; McKenzie, E.H.C.; Huang, S.K.; Abdel-Wahab, M.A.; Daranagama, D.A.; Dayarathne, M.; D'souza, M.J.; Goonasekara, I.D.; et al. Towards a Natural Classification and Backbone Tree for Sordariomycetes. Fungal Divers. 2015, 72, 199-301. [CrossRef]

76. Herrera, C.S.; Rossman, A.Y.; Samuels, G.J.; Lechat, C.; Chaverri, P. Revision of the Genus Corallomycetella with Corallonectria Gen. Nov. for C. jatrophae (Nectriaceae, Hypocreales). Mycosystema 2013, 32, 518-544.

77. Wang, Y.-Z. Three Species Excluded from Melanopsamma (Ascomycetes). Mycotaxon 2011, 115, 365-368. [CrossRef]

78. Castlebury, L.A.; Rossman, A.Y.; Sung, G.H.; Hyten, A.S.; Spatafora, J.W. Stachybotrys, Multigene Phylogeny Reveals New Lineage for Chartarum, the Indoor Air Fungus. Mycol. Res. 2014, 108, 864-872. [CrossRef]

79. Gao, Y.; Liu, F.; Duan, W.; Crous, P.W.; Cai, L. Diaporthe Is Paraphyletic. IMA Fungus 2017, 8, $153-187$. [CrossRef] [PubMed]

80. Hongsanan, S.; Maharachchikumbura, S.S.N.; Hyde, K.D.; Samarakoon, M.C.; Jeewon, R.; Zhao, Q.; Al-Sadi, A.M.; Bahkali, A.H. An Updated Phylogeny of Sordariomycetes Based on Phylogenetic and Molecular Clock Evidence. Fungal Divers. 2017, 84, 25-41. [CrossRef]

81. Wijayawardene, N.N.; Jayarama Bhat, D.; Hyde, K.D.; Camporesi, E.; Chethana, K.W.T.; Tangthirasunun, N.; Wang, Y. Camarosporium Sensu Stricto in Pleosporinae, Pleosporales with Two New Species. Phytotaxa 2014, 183, 16-26. [CrossRef] 